\title{
PENDAMPINGAN GURU PAUD ARI-ARI JEPARA DALAM MENINGKATKAN PEMBELAJARAN AUD BERBASIS BUDAYA
}

\author{
Yushinta Eka Farida ${ }^{1}$,Santi Andriyani ${ }^{2}$, DS. Drajad Wibowo ${ }^{3}$ \\ Fakultas Tarbiyah dan Ilmu Keguruan UNISNU Jepara, Fakultas Tarbiyah dan Ilmu Keguruan \\ UNISNU Jepara, Fakultas Sains dan Teknologi UNISNU Jepara \\ *E-mail: faridayushinta@gmail.com.
}

\begin{abstract}
Introducing culture to children is important to do by all aspect included a kindergarden institution. The partner of this program is all of kindergarden educators named Ari-Ari located in Sukosono, Kedung, Jepara, Center Java. The purposes of this program are:1) to increase the knowledge and skill about culture - based learning strategy; (2) to increase students' learning interest; 3) to increase their knowledge about learning media. The results of this program are: 1) educating about the importance of inculcating culture for children;2) training of culture based learning strategy;3) Practice teaching by partners. From this program, it hopes that it can increase and develop partners' skill which is finally able to increase children's loving for Indonesian culture.
\end{abstract}

Keywords - culture, young learner, teaching and learning

\begin{abstract}
Abstrak
Pengenalan budaya kepada anak usia dini merupakan hal yang penting yang harus dilakukan oleh semua pihak termasuk lembaga pendidikan yaitu PAUD. Mitra pada pengabdian ini adalah para guru kelompok bermain (KB) Ari-Ari yang terletak di desa Sukosono Kedung Jepara Jawa Tengah. Tujuan dari pengabdian ini adalah: (1) untuk meningkatkan kreatifitas dan keterampilan guru PAUD dalam strategi pembelajaran berbasis budaya; (2) untuk membekali pengetahuan dan keterampilan guru PAUD mengenai strategi pembelajaran berbasis budaya; (3) untuk meningkatkan minat belajar siswa; (4) untuk membekali mitra mengenai media edukatif berbasis budaya. Metode pengabdian yang digunakan adalah: edukasi, training, praktek. Hasil pengabdian ini adalah : 1) edukasi tentang pentingnya budaya bagi anak usia dini; 2) pelatihan strategi pembelajaran berbasis budaya; 3) Praktik mengajar oleh mitra. Dengan adanya pengabdian ini diharapkan dapat meningkatkan keterampilan mitra yang pada akhirnya dapat meningkatkan kecintaan anak terhadap budaya Indonesia.
\end{abstract}

Kata Kunci-budaya, anak usia dini, pembelajaran

\section{PENDAhULUAN}

Indonesia merupakan negara yang kaya akan potensi sumber daya alam dan juga kaya akan adat dan budaya. Budaya Indonesia memiliki ragam dan jenis yang terbilang banyak dan bervariasi. Budaya diartikan sebagai keseluruhan sistem berpikir, nilai, moral, norma, dan keyakinan (belief) manusia yang dihasilkan masyarakat. Sistem berpikir, nilai, moral, norma, dan keyakinan itu adalah hasil dari interaksi manusia dengan sesamanya dan lingkungan alamnya [1]. Kearifan lokal / local wisdom merupakan kecendekiaan terhadap kekayaan suatu daerah berupa pengetahuan, kepercayaan, norma, adat istiadat, kebudayaan, wawasan dan sebagainya sebagai bentuk warisan dan dipertahankan sebagai sebuah identitas dan pedoman dalam mengajarkan kita untuk bertindak secara tepat dalam kehidupan [2]. Pengenalan budaya pada anak sejak dini merupakan hal yang penting. Ketika anak mulai mengenal budaya, maka mereka akan memahami budaya Indonesia dan akan lebih menghargai segala perbedaan yang ada. Anak juga akan lebih menghormati dan merasa simpati juga empati terhadap orang lain. Pada akhirnya, anak akan lebih mencintai budaya karena cinta budaya merupakan bagian dari kecintaan anak terhadap negara republik Indonesia.

Penanaman nilai-nilai budaya bagi anak dapat diimplementasikan melalui pendidikan dan pembelajaran di PAUD. Lingkungan dan strategi pembelajaran berbasis budaya akan meningkatkan 
pemahaman dan kecintaan anak terhadap budaya. Selain itu, dengan strategi keteladanan, kedisiplinan, dan juga nasehat akan pentingnya kearifan lokal /local wisdom berdampak positif pada karakter anak [3]. Penanaman nilai budaya juga bisa dilakukan melalui media permainan. Permainan yang diterapkan sebaiknya menekankan pada budaya lokal daerah setempat, agar dapat melestarikan dan memupuk rasa cinta terhadap budaya sendiri. [4] Hasil penelitian menunjukan bahwa melalui lagu, dapat menanamkan nilai-nilai pendidikan karakter termasuk didalamnya adalah semangat kebangsaan, cinta tanah air, cinta damai, peduli lingkungan dan peduli sosial [5]. Oleh karena itu, pendidikan berbasis local wisdom (kearifan lokal) membuat seseorang merasa optimis akan terciptanya pendidikan yang mampu memberikan spirit dan makna bagi kehidupan manusia di Indonesia [6].

Lokasi mitra pada pengabdian ini adalah terletak di desa Sukosono. Sukosono terletak sebelah selatan kota Jepara kira-kira 9 KM. Berdasarkan Data Monografi, desa Sukosono memiliki luas \pm 383.352 Ha. Secara geografis Sukosono terletak 8 meter dari permukaan air laut, beriklim tropis dengan curah hujan $6,70 \mathrm{~mm} / \mathrm{th}$, temperatur suhu udara rata-rata $33{ }^{\circ} \mathrm{C}$. Sedangkan secara topografis, kondisi wilayahnya terdiri atas $73,62 \%$ tanah pekarangan, tegalan yang kering dan 26,38 $\%$ berupa tanah sawah tadah hujan. Desa Sukosono merupakan desa paling ujung utara Kecamatan Kedung, yang berbatasan sebelah: selatan Desa Kerso, Dongos, sebelah barat Desa Rau, Petekeyan, sebelah utara Desa Sukodono dan Langon, sebelah timur Desa Ngabul Mitra pada program kemitraan ini adalah lembaga pendidikan yang bergerak di ranah anak usia dini. Mitra dimaksud adalah kelompok bermain (KB) Ari-Ari. Mitra tersebut berlokasi di desa Sukosono, kecamatan Kedung, kabupaten Jepara Jawa Tengah.

Berdasarkan hasil wawancara dan observasi kepada mitra, ada beberapa persoalan yang melingkupi lembaga tersebut, yaitu: 1) kurang terampilnya mitra dalam pembelajaran berbasis budaya; 2) tidak adanya media yang dapat mendukung pembelajaran berbasis budaya; 3) tidak adanya display kelas berbasis budaya; dan 4) kurang antusiasnya siswa/anak dalam pembelajaran berbasis budaya. Ini sesuai dengan hasil penelitian yang dilakukan oleh Oktaviani menunjukkan bahwa permasalahan pendidikan selama ini adalah sumber dan bahan ajar yang berkaitan dengan budaya lokal masih minim [7]. Maka dari itu, sesuai dengan kesepakatan mitra, prioritas permasalahan yang akan mendapatkan solusi adalah: 1) kurang terampilnya mitra dalam pembelajaran berbasis budaya; 2 ) tidak adanya media yang dapat mendukung pembelajaran berbasis budaya.

Adapun tujuan dari PKM ini adalah : (1) untuk meningkatkan kreatifitas dan keterampilan guru PAUD dalam strategi pembelajaran berbasis budaya ; (2) untuk membekali pengetahuan dan keterampilan guru PAUD mengenai strategi pembelajaran berbasis budaya; (3) untuk meningkatkan minat belajar siswa; (4) untuk membekali mitra mengenai media edukatif berbasis budaya. Pentingnya pembelajaran berbasis budaya bagi anak usia dini juga didukung beberapa hasil penelitian, diantaranya :

Tabel 1

Hasil Penelitian yang Berkaitan dengan Program

\begin{tabular}{l|l|lll}
\hline No & Judul dan Penulis & Hasil & \\
\hline 1 & $\begin{array}{l}\text { Penanaman Nilai- } \\
\text { Nilai Karakter } \\
\text { Melalui }\end{array}$ & Hasil dari penelitian menunjukan bahwa \\
\hline & $\begin{array}{l}\text { Kegiatan } \\
\text { Storytelling } \\
\text { dengan } \\
\text { Menggunakan }\end{array}$ & kegiatan storytelling dengan menggunakan \\
\hline & $\begin{array}{l}\text { Cerita Rakyat } \\
\text { Sasak pada Anak } \\
\text { Usia Dini [8] }\end{array}$ & cerita rakyat mampu untuk menanamkan nilai- \\
\hline & & nilai karakter. Karakter yang muncul \\
\hline & & merupakan sebuah akumulasi yang muncul dari \\
\hline & & perilaku anak-anak setelah mendengarkan \\
\hline
\end{tabular}




\begin{tabular}{|c|c|c|}
\hline & & Lendong Kaoq” dan “ Tegodek-godek dan \\
\hline & & Tetunteltuntel" \\
\hline \multirow[t]{2}{*}{2} & $\begin{array}{l}\text { Pengenalan } \\
\text { Budaya Melalui } \\
\text { Metode Bercerita } \\
\text { untuk Anak Usia } \\
\text { Dini oleh Yulfrida } \\
\text { Rahmawati [9] }\end{array}$ & $\begin{array}{l}\text { Hasil dari penelitian ini Pengenalan budaya lokal akan lebih } \\
\text { bermakna dan menarik tentunya dengan cara mendengarkan } \\
\text { cerita. Dengan proses } \\
\text { pengembangan imajinasinya anak diharapkan dapat berubah pola } \\
\text { pikir sesuai dengan nilainilai budaya }\end{array}$ \\
\hline & & yang ingin disampaikan \\
\hline \multirow[t]{9}{*}{3} & $\begin{array}{l}\text { Meningkatkan } \\
\text { Nilai-Nilai } \\
\text { Karakter Anak } \\
\text { Usia Dini }\end{array}$ & Hasil dalam penelitian ini menunjukkan respon \\
\hline & $\begin{array}{l}\text { Melalui } \\
\text { Penerapan Metode } \\
\text { Proyek oleh } \\
\text { Mimin }\end{array}$ & positif yang ditunjukkan oleh kemunculan perilaku \\
\hline & Hamidah [10] & anak dalam nilai tanggung jawab, \\
\hline & & komunikatif dan kerjasama. Pada akhir siklus \\
\hline & & mengalami peningkatan yang cukup baik. Sebagian \\
\hline & & besar anak \\
\hline & & dapat mencapai indikator dengan kategori \\
\hline & & berkembang sesuai harapan dan berkembang sangat \\
\hline & & baik. \\
\hline
\end{tabular}

\section{METODE}

Tahapan atau langkah-langkah yang ditempuh guna melaksanakan solusi atas permasalahan spesifik yang dihadapi oleh mitra meliputi Edukasi, Training, dan Pendampingan dengan rincian sebagai berikut:

Tabel 2 Metode Pelaksanaan Pengabdian

\begin{tabular}{|c|c|c|}
\hline \multirow{2}{*}{\multicolumn{3}{|c|}{ Lanokah-lanokah }} \\
\hline & Kegiatan & Langkah-langkah \\
\hline 01 & $\begin{array}{lr}\text { Pelatihan dan } & \text { Edukasi } \\
\text { mengenai } & \text { pentingnya } \\
\text { pembelajaran } & \text { berbasis } \\
\text { budaya bagi anak usia dini }\end{array}$ & $\begin{array}{l}\text { - Koordinasi dengan mitra terkait waktu dan } \\
\text { tempat } \\
\text { - Membuat materi pelatihan } \\
\text { - Metode pelatihan yang digunakan } \\
\text { adalah: lecturing, wacthing video, dan } \\
\text { praktek } \\
\text { - Diskusi dan Brainstorming }\end{array}$ \\
\hline 02 & $\begin{array}{l}\text { Pendampingan simulasi dan } \\
\text { praktik pembelajaran } \\
\text { berbasis budaya }\end{array}$ & $\begin{array}{l}\text { - Koordinasi dengan mitra terkait waktu dan } \\
\text { tempat } \\
\text { - Membuat materi pelatihan } \\
\text { - Mengkonsep materi praktek } \\
\text { - Metode pendampingan yang digunakan adalah: } \\
\text { lecturing, small group discussion, dan simulasi } \\
\text { - Performance }\end{array}$ \\
\hline 03 & $\begin{array}{l}\text { Pendampingan mitra real } \\
\text { practice } \\
\text { pembelajaran berbasis } \\
\text { budaya }\end{array}$ & $\begin{array}{l}\text { - Koordinasi dengan mitra terkait waktu } \\
\text { - Membuat instrumen observasi kelas } \\
\text { - Metode pendampingan yang digunakan adalah: } \\
\text { performance dan konseling }\end{array}$ \\
\hline
\end{tabular}




\section{HASIL DAN PEMBAHASAN}

Berdasarkan metode pelaksanaan yang dirancang, maka hasil dari pengabdian sebagai berikut : Pertama, kegiatan ini diawali dengan kegiatan ceremonial sebagai acara pembuka untuk kegiatan yang dilaksanakan selama tiga hari. Acara ini diisi dengan beberapa sambutan yaitu dari Tim PKM yang menjelaskan maksud dan tujuan program, perwakilan dari mitra yang menyampaikan antusiasme dan apresiasi mengenai kegiatan PKM ini. Adapun hasil dari ceremonial ini adalah terwujudnya komunikasi yang harmonis dan sinergis terkait dengan program PKM yang dilaksanakan.

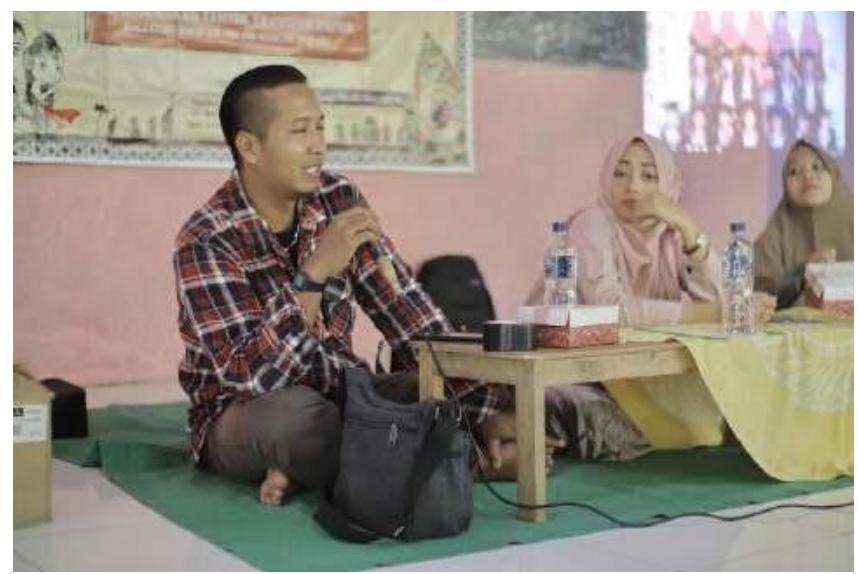

Gambar 1. Pembukaan Acara PKM

Kedua, kegiatan selanjutnya adalah pemaparan materi oleh salah satu tim dengan tema “ Pentingnya pembelajaran berbasis budaya bagi anak usia dini. Kegiatan ini diawali dengan ice breaking untuk memecah suasana forum supaya tidak jenuh dan membosankan. Materi ini berisi tentang definisi budaya, macam-macam budaya indonesia, pentingnya budaya bagi AUD (Anak Usia Dini), startegi pembelajaran berbasis budaya. Metode yang digunakan dalam kegiatan ini adalah lecturing, brainstorming, dan discussion. Hasil dari kegiatan ini adalah mitra antusias dan aktif bertanya.

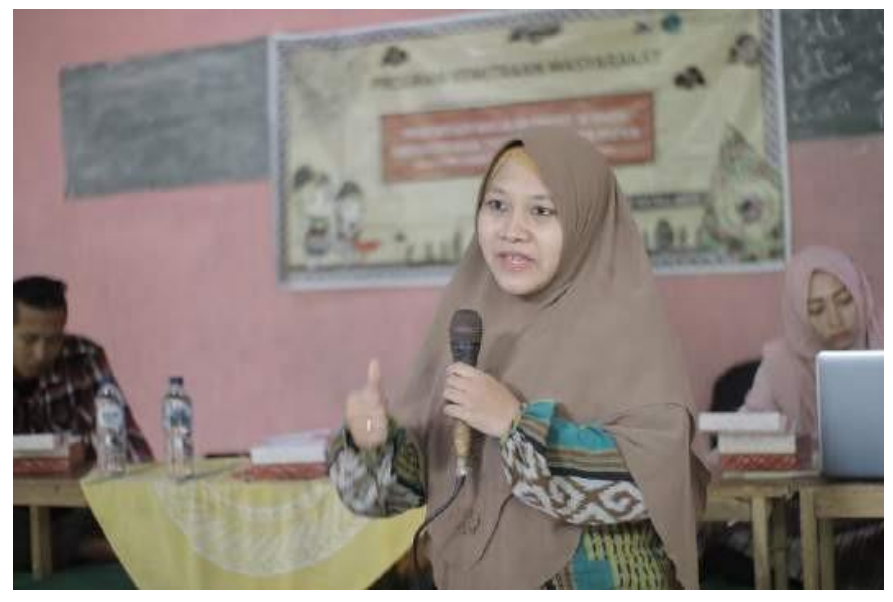

Gambar 2. Pemaparan Materi tentang Strategi Pembelajaran berbasis Budaya

Ketiga, kegiatan selanjutnya adalah pendampingan simulasi mitra mengenai strategi pembelajaran berbasis budaya. Kegiatan ini diawali dengan pembagian kelompok dan penentuan strategi pembelajaran, yaitu metode bercerita, story telling, dan parodi. Selanjutnya, tiap kelompok melakukan diskusi dan persiapan untuk melakukan simulasi di depan audience. Hasil dari kegiatan ini adalah performance per kelompok terbilang cukup maksimal dan para audience terlihat antusias. 


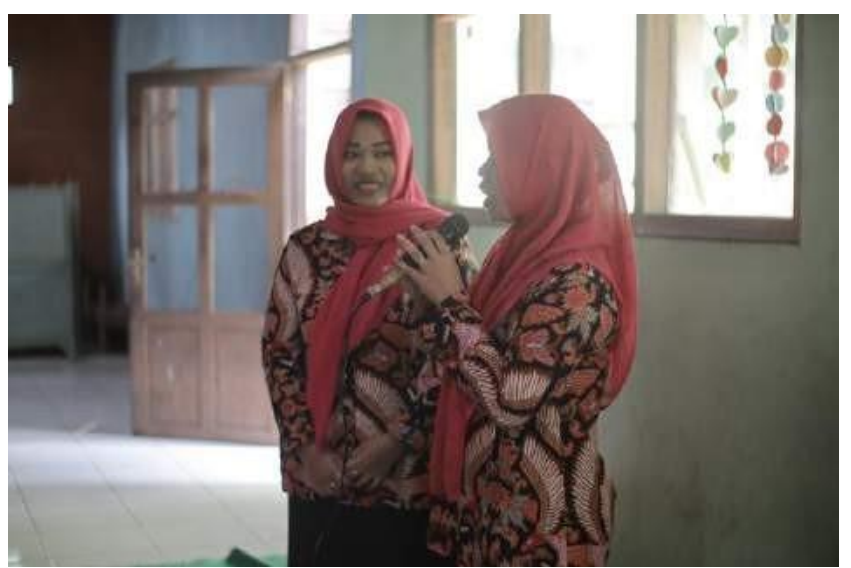

Gambar 3. Mitra sedang melakukan simulasi pembelajaran berbasis budaya

Keempat, pengabdian selanjutnya adalah pendampingan dan monitoring kepada mitra saat implementasi pembelajaran berbasis budaya menggunakan media papan wayang. Kegiatan ini ada beberapa tahapan yaitu :

Tabel 3

Tahapan Pembelajaran Berbasis Budaya bagi AUD

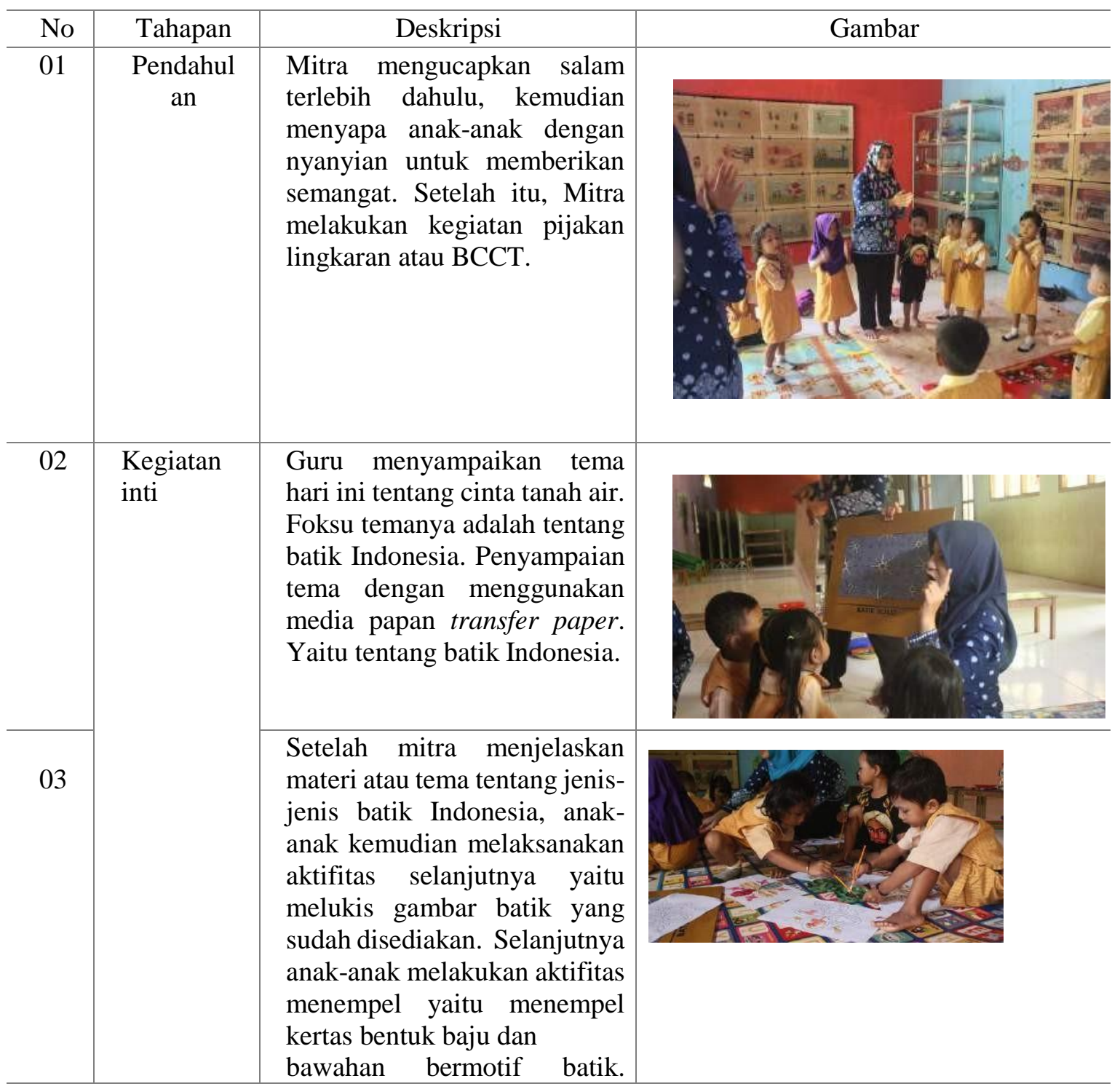




\begin{tabular}{l|l|l|l}
\hline & $\begin{array}{l}\text { Anak-anak terlihat senang dan } \\
\text { antusias dalam mengikuti } \\
\text { kegiatan tersebut. }\end{array}$ \\
& $\begin{array}{l}\text { Hal ini sesuai dengan hasil } \\
\text { penelitian yang menunjukkan } \\
\text { bahwa bahwar model } \\
\text { pembelajaran berbasis } \\
\text { kearifan lokal dapat } \\
\text { meningkatkan kreatifitas dan } \\
\text { hasil belajar siswa [11] }\end{array}$ \\
\hline 03 & Penutup & $\begin{array}{l}\text { Guru melakukan recalling atas } \\
\text { kegiatan yang telah dilakukan } \\
\text { bersama anak-anak melalui } \\
\text { games dan parodi. Kemudian } \\
\text { terakhir ditutup dengan } \\
\text { sayonara dan doa. }\end{array}$ \\
\hline
\end{tabular}

\section{KESIMPULAN}

Kesimpulan dari pengabdian yang telah dilakukan adalah:

a. Tahapan program PKM dimulai dengan edukasi mengenai pentingnya budaya bagi anak usia dini, pelatihan tentang pembelajaran AUD berbasis budaya, dan terakhir pendampingan praktik pembelajaran AUD berbasis budaya oleh Mitra.

b. Praktik mitra terkait pembelajaran berbasis budaya terdiri dari pembukaan, inti, dan penutup.

c. Hasil dari PKM ini berupa model pembelajaran berbasis budaya yaitu melalui dongeng dan parodi.

\section{SARAN}

Kekurangan dari program pengabdian ini adalah kurang variasi jenis metode yang diberikan pendampingan kepada mitra terutama untuk pembelajaran berbasis budaya. Oleh karena itu, perlu ada pengabdian lebih lanjut yang lebih komprehensif.

\section{UCAPAN TERIMA KASIH}

Tim PKM mengucapkan terimakasih kepada DRPM Hibah ristekdikti atas dukungan pendanaan sehingga program PKM berjalan dengan lancar. Selain itu, kami juga menyampaikan terimakasih kepada LPPM UNISNU Jepara atas bimbingan dan arahan sehingga program berjalan sesuai dengan harapan.

\section{DAFTAR PUSTAKA}

[1] Panggayudi, D. S., Suweleh, W., \& Ihsan, P. (2017). Media Game Edukasi Berbasis Budaya untuk Pembelajaran Pengenalan Bilangan pada Anak Usia Dini. MUST: Journal of Mathematics Education, Science and Technology, 2(2), 255-266.

[2] Utari,U. Degeng,S.Nyoman, Akbar, S. (2016) Pembelajaran Tematik Berbasis Kearifan Lokal Di Sekolah Dasar Dalam Menghadapi Masyarakat Ekonomi ASEAN (MEA). Jurnal Teori dan Praksis Pembelajaran. Pendidikan Dasar Pascasarjana Universitas Negeri Malang

[3] Rahayu, S. (2018). Penanaman Nilai-Nilai Kearifan Lokal Dalam Pembentukan Karakter Anak Usia Dini Di Kecamatan Marioriwawo Kabupaten Soppeng (Doctoral Dissertation, Universitas Negeri Makassar).

[4] Karwati, E. (2016). Pengembangan Pembelajaran Dengan Menekankan Budaya Lokal Pada 
Pendidikan Anak Usia Dini. EDUHUMANIORA: Jurnal Pendidikan Dasar, 6(1).

[5] Arostiyani, D. (2013). Pemanfaatan Lagu Anak-anak sebagai Media Pendidikan Karakter di Taman Kanak-kanak Aisyiyah Desa Linggapura Kecamatan Tonjong, Brebes (Doctoral dissertation, Universitas Negeri Semarang).

[6] Setiawan, Benni. (2008). Agenda Pendidikan Nasional. Yogyakarka : Ar-Ruz Media Group

[7] Oktavianti, Zuliana, ratnasari, 2017. Menggagas Kajian Kearifan Budaya Lokal Di Sekolah Dasar Melalui Gerakan Literasi Sekolah. FKIP Universitas Muria Kudus

[8] Ramdhani, S., Yuliastri, N. A., Sari, S. D., \& Hasriah, S. (2019). Storytelling: Inculcation Character Value with Using Sasak Folkflore. Jurnal Obsesi: Jurnal Pendidikan Anak Usia Dini, 3(1), 133-139.

[9] Rahmawati, Y. (2012). Pengenalan Budaya Melalui Bercerita untuk Anak Usia Dini. Jurnal Pendidikan Anak, 1(1).

[10] Hamidah, M. (2017). Meningkatkan Nilai-Nilai Karakter Anak Usia Dini Melalui Penerapan Metode Proyek. Tunas Siliwangi: Jurnal Program Studi Pendidikan Guru Paud Stkip Siliwangi Bandung, 3(1), 21-37.

[11] Pamungkas.A, Subali.B, Lunuwih.S. 2017. Implementasi Pembelajaran IPA Berbasis Kearifan Lokal untuk Meningkatkan Kreatifitas dan Hasil Belajar. Jurnal Inovasi Pendidikan IPA. Universitas Negeri Yogyakarta. 